\title{
O DESIGN COMO ESTRATÉGIA DE COMPETITIVIDADE: A CONCEPÇÃO DE UMA IDENTIDADE REGIONAL
}

\section{DESIGN AS A STRATEGY FOR COMPETITIVENESS: THE DESIGN IDENTITY OF A REGIONAL}

\author{
Daiane Aparecida de Melo Heinzen ${ }^{1}$; Marco Aurélio Petrelli ${ }^{2}$; Carlos Marcelo Ardigó ${ }^{3}$; Nelson \\ Casarotto Filho ${ }^{4}$ \\ ${ }^{1}$ Instituto Federal de Santa Catarina - IFSC - Jaraguá do Sul- Brasil \\ dheinzen@ifsc.edu.br \\ ${ }^{2}$ Universidade do Vale do Itajaí - UNIVALI - Balneário Camboriú - Brasil \\ petrelli@univali.br \\ ${ }^{3}$ Universidade do Vale do Itajaí - UNIVALI - Balneário Camboriú - Brasil \\ marcelo.ardigo@ifes.com.br \\ ${ }^{4}$ Universidade Federal de Santa Catarina - UFSC - Florianópolis - Brasil \\ casarotto@deps.ufsc.br
}

\begin{abstract}
Resumo
Inserido em mercados industriais, a formação de Clusters estabelece um modelo de competitividade consolidado, baseado na atuação em grupo, dirimindo deficiências competitivas individuais. Esta pesquisa tem por objetivo compreender a percepção de profissionais de design de diferentes segmentos de mercado a respeito da construção de uma identidade regional com base em design, reforçando a marca de sua região. A metodologia utilizada para seu desenvolvimento é de uma pesquisa exploratória e descritiva, proporcionando maior aprofundamento quanto ao foco deste estudo, possibilitando ainda o estabelecimento de relações entre variáveis, abordando três pontos específicos: Clusters, Design e a Identidade Regional. A coleta de dados foi realizada por meio de um Focus Group, contando com a participação de quatro profissionais da área têxtil, escolhidos a partir de seu envolvimento com o tema: professores universitários em curso de Design de Moda e com atuação profissional na área têxtil e de acessórios. Percebe-se a partir do posicionamento dos profissionais participantes deste estudo, um cenário positivo, compreendendo a identidade no design como uma estratégia competitiva para grupos produtivos regionais, se considerados todos os participantes deste processo: poder público; instituições públicas e privadas.
\end{abstract}

Palavras-chave: clusters; design; identidade regional.

\section{Introdução}

A economia mundial apresenta novas características, alterando as relações mercadológicas e estabelece paradigmas diferentes aos até então existentes, onde a extrema valorização ao processo, à 
indústria, à produção, desencadeada pela concepção de novas máquinas e de novas tecnologias, circunstância deflagrada pela Revolução Industrial, passa a atribuir ao homem a capacidade de estabelecer um relacionamento mais consistente com produtos e serviços, determinando tendências, estabelecendo suas prioridades, fazendo suas escolhas.

Segundo Schlemper e Gontijo (2007) a mudança da estrutura social, cultural, política e econômica da humanidade estão relacionadas à profunda revolução que a sociedade vem vivenciando. Atualmente, depara-se com uma sociedade dinâmica, instável e globalizada, onde os consumidores estão cada vez mais críticos e a concorrência mais acirrada.

Inserido num universo corporativo competitivo, a economia globalizada estimula às empresas a busca por novas bases conceituais que promovam o fortalecimento do relacionamento comercial entre todos os atores envolvidos, aumentando a responsabilidade dos gestores corporativos quanto à implantação de estratégias que posicionem suas ações de forma mais dinâmica, proporcionando a adequação de seus atos ao mercado. Surge, em decorrência deste contexto, a formação dos pólos industriais e com isto a promoção de produções e economias regionais a patamares maiores que os vislumbrados quando da atuação individual, baseados nas estratégias do grupo, estabelece um posicionamento mais adequado frente às economias industriais emergentes.

Ao design, definido sumariamente como algo relacionado à estética, responsável somente pela aparência dos produtos, são atribuídos novos sentidos, novas responsabilidades. $\mathrm{O}$ design de outrora amadurece, ganha amplitude em sua área de atuação e estabelece, ao analisado cenário atual, uma relação direta com a estratégia de posicionamento de uma empresa.

O problema de pesquisa deste estudo se estrutura a partir da consciência da existência dos Clusters e em razão de sua natureza; a busca por um diferencial competitivo proporcionado por ações coletivas. Ao design, já amplamente aplicado de maneira individualizada, proporcionando a identificação almejada a partir de identidades corporativas, se apresenta um novo desafio; a construção de um design regional.

A partir do panorama apresentado, o problema de pesquisa enfoca a investigação sobre como o design pode ser utilizado para estabelecer uma vantagem competitiva e formaliza a seguinte questão: é possível conceber uma identidade regional com base no design com objetivo de estabelecer uma vantagem competitiva?

Neste contexto, o objetivo geral deste estudo é compreender a percepção de profissionais de design de diferentes segmentos de mercado a respeito da construção de uma identidade regional com base em design. 


\section{Referencial teórico}

\subsection{Design}

Em seu discurso a respeito da atuação do design como um diferencial competitivo, Santos (2005) propõe duas situações para a atuação do design. Primeiramente, sob a ótica do design operacional, sua responsabilidade no tocante ao desenvolvimento de produtos, concebendo conceitos e tangibilizando suas idéias. Ao atuar de maneira estratégica, ao design a responsabilidade de construir relações entre as diversas variáveis relacionadas: a) Mercado: estabelecendo a relação entre as necessidades de seus clientes a partir da compreensão de seu contexto; b) Processo: responsabilizando-se pelo controle das dinâmicas envolvidas (controle de cronograma, técnicas e ferramentas, recursos humanos, insumos, processos fabris, e etc.). Identificam-se nas palavras do autor, perfis diferenciados porem complementares para atuação profissional, estabelecendo uma relação interdependente entre execução e controle, do operacional ao estratégico, evidenciando a estratégia com base no design.

Ao elevar o design ao patamar estratégico de uma empresa, Mozota (2006) identifica uma prática fundamentada em quatro princípios, que ao atuarem em conjunto, reforçam os atributos de um produto e conseqüientemente de uma marca. O design, segundo a visão do autor deve atuar como um elemento de diferenciação e desta maneira, proporcionar vantagem competitiva de mercado através do valor de marca, proporcionando maior lealdade dos clientes e conseqüentemente, preços mais competitivos.

Ao atuar como integrador, o design possibilita o incremento ao processo de desenvolvimento de novos produtos ao atuar de maneira interdisciplinar, considerando diversas variáveis e atores para sua realização. Ao considerar o design como um elemento de transformação, o autor considera que a sua atuação pode criar oportunidades de novos negócios, melhorando a habilidade da corporação para lidar com mudanças e conseqüentemente melhor resposta as nuances de competitividade. Por fim, ao compreender o design como um bom negócio, o autor identifica seu grande potencial como fonte para aumento de vendas e margens de lucro, proporcionando maior valor de marca, participação de mercado e melhor retorno sobre investimento.

A prática do design concebida a partir de uma visão estratégica vem tomando "novas" proporções e determinando a retórica ao se referir ao assunto. Franzoi (2009) e Merino (2010) posicionam-se de maneira coincidente ao apresentarem como base de suas argumentações com foco na produção agrícola familiar, a importância do design para reforçar os princípios de competitividade, diferenciação e sustentabilidade. Atuando desta maneira, o design pode estar 
inserido nos grupos produtivos, conectando as informações de mercado com as características regionais, evidenciando a diferenciação por meio de uma identidade singular.

Flores et al (2009) apresenta a comunicação deficiente entre produtor e consumidor final como um dos grandes entraves para os produtos desenvolvidos por pequenos produtores. Sugere-se a partir desta ótica, que o estabelecimento de melhores mecanismos de identificação dos produtos regionais, tornar-se-ia possível ampliar essa relação, fornecendo meios para construir elementos de competitividade e promover a sua inserção no mercado de forma efetiva e eficiente.

Para Queluz (2008) o design pode a partir de sua práxis, reforçar as características que estabelecem uma linguagem impar, proporcionando um posicionamento único e desta maneira estratégico. Sob esta ótica, compreende-se que o designer deve pensar o produto e estabelecer uma relação direta entre a imagem e identidade, evidenciando em seus artefatos, os valores relativos à sociedade e cultura de sua região. Cria-se desta maneira uma identidade regional.

Este cenário pode ser percebido como uma realidade a partir de estudos como o Cara Brasileira1; uma parceria entre o Serviço Brasileiro de Apoio a Micro e Pequenas Empresas SEBRAE e o Departamento de Ciências Sociais da Universidade Federal de Alagoas - UFAL. Este estudo tem como objetivo principal criar condições para evidenciar a identidade cultural a produtos e serviços como estratégia de ampliar os negócios, mas especialmente aos desenvolvidos por micro e pequenas empresas, que de acordo com Queluz (2008) são detentoras de uma genuína autenticidade.

Segundo os autores do projeto, dois aspectos são fundamentais na ação do Cara Brasileira:

a) Valorização das identidades culturais como estratégia de criação da autoestima e da criação e/ou fortalecimento do sentimento de pertencimento a um local, território, APL's;

b) Agregar valor aos produtos e serviços e ao formato de negócios, diferenciar destinos turísticos e em diversos setores produtivos (móveis, têxteis, agronegócios, etc.) que evidentemente possam se distinguir a partir de valores da cultura local.

Desta maneira é possível perceber a representatividade ao relacionar o design à construção de uma identidade regional, pois se percebe que a utilização do design como valor agregado é uma tendência no mercado mundial que aposta em um produto singular, único e exclusivo. Essa ferramenta (design) pode ser utilizada para, entre outros elementos, conceber produtos e conseqüentemente, construir uma identidade forte e com linguagem própria, adaptados as novas necessidades de Mercado.

Este estudo encontra-se alinhado a uma linha de pensamento, cada vez mais expressiva, aqui representada nas palavras de Moraes (2010, p 71). Na visão do autor, a capacidade dos produtores torna-se imperativa, principalmente no tocante a interpretação do estilo de vida local, para que seja 
inserido como componente diferencial, de caráter sólido, nos produtos que competem hoje em nível global, proporcionando, por sua vez, aos consumidores, novas experiências de consumo.

A abordagem do autor deve ser considerada aqui como um recorte, um pensamento representativo de um posicionamento maior, ressaltando a identidade local, por meio do conceito de valorização do território (terroir), apontado como um modelo de diferenciação para os bens de produção industrial contemporânea. Complementa o autor, que ao contemplar o território de origem e a sociedade que a compõe, o terroir abrange o capital simbólico do produto (relações socioculturais, características do território, entre outros) culminando por definir a configuração de artefatos, tradições, manifestações culturais, formando, por fim, o patrimônio material e imaterial de caráter marcante e simbólico e que determina por vez o produto local.

\subsection{Clusters}

Clusters $^{2}$, aglomerados ${ }^{3}$, Arranjos Produtivos Locais ${ }^{4}$, pólos industriais ${ }^{5}$; muitas são as denominações para designar uma concentração de empresas que atuam de forma conjunta e desta forma, promoverem economia e a sociedade de suas regiões, integrando os diferentes agentes cujas relações possibilitam fornecer um conjunto de recursos que os tornem capacitados ao exercício de determinada atividade econômica.

Segundo Casarotto Filho e Pires (2001, pg. 69) um cluster desenvolve-se sobre a vocação regional e pode conter empresas produtoras de produtos finais, verticalizar-se a jusante (serviços) ou a montante (fornecedores), além de incluir associações de suporte privadas ou ligadas ao governo.

Para Cunha e Cunha (2005) as características relevantes em Clusters são: troca de informações entre firmas, instituições e indivíduos inseridos no cluster, existência de uma diversificada infra-estrutura institucional de apoio às atividades desenvolvidas, presença de uma identidade sociocultural, vantagens competitivas coletivas, desenvolvimento de especialização coletiva, implementação de ações estratégicas entre os agentes, organização simultânea de relações de concorrência e cooperação entre os agentes.

1 www.carabrasileira.sebrae.com.br

2 “[...] rede de indústrias afins fisicamente próximas umas das outras.” (FENSTERSEIFER, 1995, p. 26)

3 "[...] agrupamento geograficamente concentrado de empresas inter-relacionadas e instituições correlatas numa determinada área vinculadas por elementos comuns e complementares.” (PORTER, 1999, p. 211)

4 Aglomeração de empresas definidas por critérios simultaneamente regionais e setoriais (SEBRAE, 2007)

5 “....] regiões industrializadas formadas por uma ou várias cidades que abrigam empresas industriais ligadas a um eixo de atividade econômica principal como ofertadora de produtos, insumos, componentes e serviços

especializados.” (CARVALHO JÚNIOR, 2007, p. 11) 
Sob a ótica de Carvalho Júnior (2007) os pólos industriais constituem uma forma de organização da produção que possibilita às empresas construírem vantagens competitivas sustentadas não somente por ações individuais, mas também por ações coletivas. Complementando esta visão, Porter (1999) apresenta também o fator geográfico ao definir os pólos industriais, pois estes são os resultantes de um agrupamento geograficamente concentrado de empresas interrelacionadas e instituições correlatas numa determinada área, vinculadas por elementos comuns e complementares.

Em nível mundial, a existência dos pólos industriais tem sido considerada estratégica, reforçando o caráter competitivo de países e regiões, objetivando seus posicionamentos mercadológicos, associados à realização das atividades concentradas em dado território, com a presença de um grande número de agentes econômicos ligados àquelas atividades; situação já observada em países como a Inglaterra e a Itália no século XVIII e de forma muito mais difundida nos dias atuais (PORTER, 1999).

Não obstante a esta tendência mundial, o complexo industrial brasileiro vem apresentando dentro de seu recente histórico, a sua adequação a esta realidade, como é possível perceber a partir do Levantamento dos APL's realizado pelo MDIC (2008) que mapeou os APL's brasileiros e identificou a existência de 260 APL's existentes em todos os 26 estados da federação e o Distrito Federal.

Os números apresentados no levantamento realizado pelo MDIC (2008), não representam a totalidade do complexo industrial brasileiro, mas sim os grupos industriais que apresentam, dentre outras características, uma atividade produtiva predominante; que compartilham formas percebidas de cooperação e algum mecanismo de governança. Fazem parte deste formato diversos setores produtivos, como por exemplo: o setor turístico, agrícola, moveleiro, de tecnologia da informação, calçadista, entre outros.

\subsection{Competitividade}

Considerando o atual contexto, baseado em uma competição globalizada, no qual a visão concorrencial precisa e vem sendo ampliada para além da concorrência direta e isolada, incorporando considerações genéricas e de competição entre redes e cadeias, a construção de uma estratégia robusta para o alcance de vantagens competitivas duradouras se sobressaem.

A competitividade consiste em criar vantagens competitivas, em que a empresa busca a obtenção de características que as diferenciem das demais. Slack (1993) corrobora nesta idéia de forma simplificada, mencionando que a competição entre os participantes do mercado é que determinará o nível de competição no setor. O autor argumenta que um desempenho superior em 
um conjunto de fatores que leva uma organização a ganhar mais pedidos do que seus concorrentes é o que comprova que a ganhadora é mais competitiva do que as demais.

A concorrência em uma indústria apresenta raízes em sua estrutura econômica básica e depende de cinco forças competitivas, consolidadas por Porter (1986) como: entrada, ameaça de substituição, poder de negociação dos compradores, poder de negociação dos fornecedores e rivalidade entre os atuais concorrentes, as quais refletem o fato de que a concorrência em uma indústria não está limitada aos participantes estabelecidos.

Desta forma, as cinco forças determinam a lucratividade, os custos que têm de suportar e o investimento necessário para competir. O objetivo da estratégia de uma empresa, no contexto de uma indústria, é o de encontrar uma posição onde seja possível melhor se defender contra essas forças ou influenciá-las em seu favor. Ainda, segundo Porter (1986), as organizações contam com três abordagens estratégicas genéricas para enfrentar as cinco forças competitivas dentro de um contexto no qual todas as empresas competem: liderança no custo total, diferenciação e enfoque. Estas abordagens estratégicas representam os possíveis caminhos para a superação dos concorrentes em uma indústria e para a criação da vantagem competitiva.

Porter (1989) observa que a vantagem competitiva está fundamentada no valor que uma organização pode oferecer aos seus mercados, de tal forma que ultrapasse o custo de produção daquilo que é oferecido pela empresa a este mercado. A mesma pode ser constituída nas inúmeras atividades distintas que uma organização desenvolve e executa, sejam elas atividade de produção, marketing, entrega e suporte, as quais contribuem para uma situação de custos relativos ou na constituição de uma base sólida de diferenciação.

Ao considerar as três estratégias genéricas, Porter (1996 a, p.49) ressalta que uma empresa pode adotar com sucesso mais do que uma abordagem, embora seja raramente possível. Porter (1996b, p.2) complementa acrescentando que a vantagem competitiva surge fundamentalmente do valor que uma empresa consegue criar para os seus compradores e que ultrapassa o custo de fabricação pela empresa. Finaliza, afirmando que a base fundamental do desempenho acima da média, no longo prazo, é a vantagem competitiva sustentável que só pode ser conquistada a partir de baixo custo ou diferenciação.

Já Hitt et al (2001), diz que a empresa, para atingir a vantagem competitiva sustentável com maior retorno do investimento no longo prazo, pode necessitar da realização das duas estratégias simultaneamente, custo e diferenciação.

Thompson e Strickland III (2000) apresentam, além das estratégias genéricas desenvolvidas por Porter, uma outra que denominaram de estratégia de provedor de melhor custo, que nada mais é do que a perseguição simultânea da estratégia de liderança de custos com a de diferenciação. 
Desta forma, o que determina a lucratividade das empresas está relacionado à sua postura estratégica, onde as estratégias para competir podem ser diferenciadas de diversas maneiras. As dimensões estratégicas em geral captam as diferenças possíveis entre as opões estratégicas de uma companhia em uma dada indústria, onde cada dimensão pode ser descrita para uma empresa em diferentes níveis de detalhes, acrescentando novas dimensões a essas. Exemplos dessas dimensões são: especialização, identificação de marcas, política de canal, seleção do canal, qualidade do produto, liderança tecnológica, integração vertical, posição de custos, atendimento, entre outros.

Prahalad e Hamel (1998, p. 297) discorrem que "a longo prazo a competitividade deriva de uma capacidade de formar, a custos menores e com mais velocidade do que os concorrentes, as competências essenciais que propiciam produtos que não podem ser antecipados".

Segundo os autores, as competências essenciais visam delimitar necessariamente habilidades que supram e alavanquem a vantagem estratégica das empresas, com o objetivo final de materializar os produtos essenciais alinhados as estratégias das unidades de negócios.

Para Churchill e Peter (2000) tem vantagem competitiva aquele competidor que possui a capacidade de ter seu desempenho acima do desempenho de seus concorrentes, em algo que seu mercado consumidor potencial valorize.

Portanto o competidor que possui vantagem competitiva no que oferece ao mercado é aquele que oferece maior valor agregado e benefícios aos seus clientes. Evidentemente o design pode constituir-se em uma dessas características que tornam as empresas mais competitivas a partir de uma criação de valor superior ao mercado.

O autor desenvolve um modelo denominado "Diamante da vantagem competitiva nacional", detalhado na Figura 1, o qual indica que a mesma está implicitamente ligada a quatro atributos: condições de fatores; condições de demanda; setores industriais correlatos e de apoio e a estratégia; estrutura e rivalidade das empresas locais, que tanto isolados e/ou como sistemas lapidam o diamante. $\mathrm{O}$ primeiro atributo, as condições de fatores, dizem respeito aos fatores de produção, tais como recursos humanos qualificados; recursos físicos e infra-estrutura necessária para competir em um determinado setor; recursos de conhecimento, ou seja, uma base científica, técnica e de mercado sólida; recursos de capital, entre outros.

A vantagem competitiva depende da eficiência e da efetividade com que os fatores são distribuídos e aproveitados. O segundo fator, as condições de demanda, dizem respeito à natureza da demanda do mercado doméstico para os bens e serviços do setor, e determina o rumo e o caráter da melhoria e inovação pelas empresas do país. São três os atributos gerais significativos da demanda interna: a composição, ou seja, a natureza das necessidades dos consumidores; o tamanho e o padrão de crescimento da demanda; e os mecanismos pelos quais a preferência interna é 
transmitida aos mercados externos. A composição da demanda interna determina a forma segundo a qual as organizações percebem, interpretam e reagem às necessidades dos consumidores.

Figura 1 - Determinantes da vantagem competitiva nacional

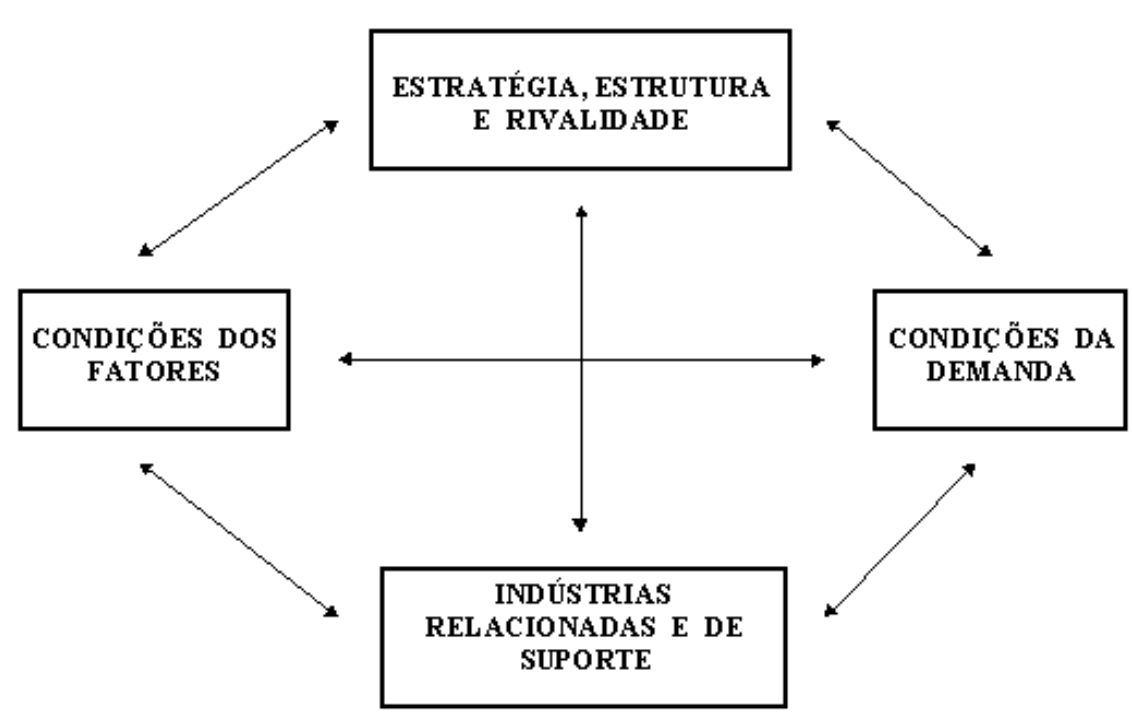

Fonte: Porter (1999, p. 179)

Terceiro, os setores industriais correlatos e de apoio refletem a importância da presença de indústrias e de fornecedores e demais setores correlatos no país, que sejam internacionalmente competitivos. Tal fato proporciona um fluxo de informações e um intercâmbio tecnológico, que é extremamente benéfico para a inovação e modernização das organizações e do país como um todo. As indústrias correlatas são aquelas nas quais as organizações, ao competirem, podem coordenar ou partilhar atividades na cadeia de valor, ou aquelas que envolvem produtos complementares. As de apoio, como o próprio termo revela, são as que proporcionam suporte às organizações principais. Por fim, a estratégia, estrutura e rivalidade de empresas apontam as circunstâncias nacionais e o contexto segundo os quais as organizações são criadas, organizadas e dirigidas, bem como qual o tipo de natureza de rivalidade interna que ocorrerá. As metas que as organizações e os indivíduos procuram alcançar, a motivação individual para o trabalho e a presença de rivais locais fortes, constituem pontos fundamentais para a criação de vantagem competitiva.

\section{Procedimentos metodológicos}

A pesquisa tem sua estrutura baseada em levantamento de dados, procedendo de forma racional e sistemática, objetivando respostas mediante o concurso dos conhecimentos disponíveis e a utilização cuidadosa de métodos, técnicas e outros procedimentos científicos, constituindo desta forma a base para este trabalho. 
Para delineamento desta pesquisa toma-se como base a taxonomia apresentada por Gil (2002) que qualifica uma pesquisa em relação a dois aspectos: quanto aos objetivos e quanto aos procedimentos técnicos utilizados. Quanto aos objetivos, propõe-se a realização de uma pesquisa exploratória e descritiva, proporcionando maior aprofundamento quanto ao foco deste estudo, possibilitando ainda o estabelecimento de relações entre variáveis.

Como forma de proceder à coleta de dados, propõe-se a realização de uma pesquisa qualitativa realizada por meio de um Focus Group,descrita por Aaker (p. 211, 2001) como “[...] o processo de obtenção de possíveis idéias ou soluções para um problema de marketing por meio da discussão do tema por um grupo de respondentes."

Este estudo toma como base, o debate a respeito do assunto a partir da percepção de profissionais de design voltados para o segmento têxtil. O debate foi realizado a partir de um Focus Group, contando com a participação de quatro profissionais da área têxtil, escolhidos a partir de seu envolvimento com o tema: todos os professores universitários em curso de Design de Moda e com atuação profissional na área têxtil e de acessórios.

\section{Resultados e análises}

Ao se questionar a respeito da possibilidade de se estabelecer uma identidade com base no design de um produto, o que se percebe a partir do relatado pelos entrevistados é uma coincidência de seus pontos de vista, considerando este um ponto estratégico na concepção de um produto e que de maneira evidente, é desconsiderado pelo mercado geral. O que ainda é identificado segundo os entrevistados, é a prática de uma cultura de apropriação de propostas já consolidadas, concebendo produtos a partir de linguagens (formatos, texturas, cores, padrões) identificadas e fornecidas por marcas renomadas.

Por mais que esta seja a realidade do segmento na visão dos entrevistados, ainda são relatadas práticas implantadas com o objetivo de reforçar uma identidade regional. No vestuário, é possível perceber em várias marcas uma identidade em produto, através do trabalho autoral dos estilistas ou designers, como por exemplo: o trabalho de Ronaldo Fraga, Gloria Coelho, da marca Lenny, entre tantas outras. Relata-se ainda, a existência do projeto Santa Catarina Moda Contemporânea, que a partir de parceria entre empresas do setor e instituições de ensino tem o objetivo de criar uma identidade de moda em Santa Catarina.

Outro ponto relatado é o identificado no segmento calçadista. Nas feiras de calçado, alguns pólos como o de Franca (SP), de Novo Hamburgo (RS) e Birigui (SP) apresentam uma marca representativa para seus produtos, identificando as empresas que compõe o pólo produtivo. Sob outro aspecto, os pólos produtivos do segmento são reconhecidos por sua vocação regional, focando sua força produtiva em função de uma segmentação de mercado. É possível exemplificar este fato 
ao identificar segundo ABICALÇADOS (2011) que o Pólo Calçadista do Vale do Rio Tijucas (SC) destina 95\% de sua produção ao segmento feminino.

Ao entender o assunto de forma positiva, compreendendo como possível a criação de uma identidade baseada no design de um produto, o debate tomou como tema a identificação das características para definição desta identidade considerada regional. Conforme relatado pelos participantes, a definição de uma identidade no design deve considerar a expressividade dos aspectos formais e conceituais característicos de uma determinada região, agregando valor ao produto por meio de soluções originais. No segmento têxtil, a inovação e a originalidade através de algo que seja autoral, podem estabelecer uma identidade competitiva.

Relata-se ainda que há alguns anos atrás, Santa Catarina (principalmente o Vale do Itajaí) era reconhecido como um pólo de referência têxtil no segmento de cama, mesa e banho, porém com a globalização e a abertura dos mercados a partir da década de 80 , muitas das empresas tradicionais neste segmento fecharam ou perderam mercado, fazendo com que a região perdesse sua identidade.

Ao se abordar a respeito da construção de um design regional como estratégia competitiva para pólos industriais, percebe-se um posicionamento positivo e coincidente por parte dos participantes, pois “o mercado está gerando um número excessivo de produtos semelhantes, em relação à qualidade, tecnologia, preço, e estética". Cabe segundo os entrevistados, entender a importância do assunto, bem como as potencialidades proporcionadas pela construção de uma base competitiva a partir de uma identidade regional atribuída ao design de um produto.

\section{Considerações finais}

A partir do panorama teórico apresentado foi possível estabelecer a relação entre assuntos distintos, mas que se coordenados de maneira estratégica podem promover o reposicionamento de produtos ou serviços, marcas ou ainda pólos produtivos. A competitividade proposta por Porter estabelece caminhos para diferenciação proporcionando parâmetros estratégicos de posicionamento mercadológico. A consciência da responsabilidade do design no desenvolvimento de produtos pode promover características únicas e exclusivas provenientes de uma determinada região, encontrando na construção de uma identidade regional, a base de sua competitividade.

A identidade com base no design de um produto estabelece uma nova estratégia competitiva, proporcionando a grupos produtivos locais, aqui denominados Clusters, a possibilidade de evidenciar e potencializar as características de sua região. Percebe-se a partir do posicionamento dos profissionais participantes deste estudo, um cenário positivo, compreendendo a identidade no design como uma estratégia competitiva para grupos produtivos regionais, se considerados todos os participantes deste processo; poder público; instituições públicas e privadas. 


\begin{abstract}
Inserted in industrial markets, the formation of clusters provides a model of competitiveness consolidated based on group performance. This research aims to understand the perception of design professionals from different market segments about the construction of a regional identity based on design, reinforcing the regional brand. The methodology used for its development is an exploratory and descriptive, providing greater depth about the focus of the study, also enabling the establishment of relationships between variables by addressing three specific points: Clusters, Design and Regional Identity. Data collection was performed using a Focus Group, with the participation of four professionals in the textile area, chosen from their involvement with the theme: all Fashion Design university professors and professional work in the textile industries. It can be seen from the placement of the professionals, a positive scenario, including the product design identity as a competitive strategy, if all participants are considered: government and public and private institutions.
\end{abstract}

Key-words: clusters; design; regional identity.

\title{
Referências
}

AAKER, D. A. Pesquisa de Marketing. São Paulo: Atlas, 2001.

CARVALHO JUNIOR, L. C. Pólos industriais do Sul do Brasil: experiências de competitividade e empreendedorismo. v 1. Florianópolis: UFSC, 2007.

CASAROTTO FILHO, N.; PIRES, L. H. Redes de pequenas e médias empresas e desenvolvimento local: estratégias para a conquista da competitividade global com base na experiência italiana. São Paulo: Atlas, 2001.

CUNHA, S. K.; CUNHA, J. C. Competitividade e sustentabilidade de um cluster de turismo. Curitiba, v. 9, n. spe2, 2005.

FLORES, M. et al. Desenvolvimento territorial rural: uma proposta de estudo para apoio à formulação de políticas públicas. In: SEBRAE (Org.). Brasília: Relume Dumará, 2009. p. 157-177.

FRANZOI, L. Diretrizes para um programa de gestão de design com foco em produtos alimentícios de grupos produtivos familiares: a ótica do consumidor e do design. Dissertação de Mestrado Pós- Graduação em Design e Expressão Gráfica - Pós-design. UFSC. Florianópolis, 2009.

GIL, A. C. Como elaborar projetos de pesquisa. São Paulo: Atlas, 2002.

HITT, M. A.; IRELAND, R. D.; HOSKISSON, R. E. Administração Estratégica. São Paulo: Thomson, 2001.

MDIC. Panorama Arranjos Produtivos Locais. Disponível em <http://www.desenvolvimento.gov.br> Acesso em 20 de abril de 2008.

MERINO, G. S. A. D. A contribuição da gestão de design em grupos produtivos de pequeno porte no setor da maricultura: O caso AMPROSUL. Dissertação (Mestrado em Design e Expressão Gráfica) - Departamento de Expressão Gráfica, UFSC: Florianópolis, 2010.

MOZOTA, B. B. The Four Powers of Design: A Value Model in Design Management. Design Management Review, Boston, v. 17, n. 2, p. 44-54, Spring 2006.

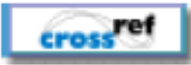

PORTER, Michael E. Competição: estratégias competitivas essenciais. Rio de Janeiro: Elsevier, 1999.

Campus, 1986.

Estratégia Competitiva - Técnicas para análise de indústrias e da concorrência. Rio de Janeiro: 
PRAHALAD, C. K.; HAMEL, G. A competência essencial da corporação. Rio de Janeiro: Campus, 1998, p. 293316.

SANTOS, F. A. N. V. MD3E (Método de Desdobramento em 3 Etapas). Tese (Doutorado) Florianópolis - UFSC, 2005.

SCHLEMPER, P. F.; GONTIJO, L. A. Design experiencial: uma oportunidade de o design aumentar o valor da marca. Anais do III Encontro Internacional da UNIDCOM/IADE. Lisboa: Centro Editorial do IADE CEIADE, 2007.

SLACK, N. Vantagem competitiva em manufatura. São Paulo: Atlas, 1993.

THOMPSON JR.; A. A.; STRICKLAND III, A.J. Planejamento Estratégico, Elaboração, Implementação e Execução. São Paulo: Pioneira, 2000.

\section{Dados dos autores:}

Nome completo: Daiane Aparecida de Melo Heinzen

Filiação institucional: Instituto Federal de Santa Catarina - IFSC

Departamento: Administração

Função ou cargo ocupado: Professora de Ensino Básico; Técnico e Tecnológico de Administração

Endereço completo para correspondência: Rua Pedro Avelino Fagundes, 45, Bairro Vila Lalau; Jaraguá do Sul/SC; Brasil; CEP: 89256-260

Telefones para contato: (47) 3370-2649

e-mail: dheinzen@ifsc.edu.br

Nome completo: Marco Aurélio Petrelli

Filiação institucional: Universidade do Vale do Itajaí - UNIVALI

Departamento: Design

Função ou cargo ocupado: Professor de Design da UNIVALI

Endereço completo para correspondência: $5^{\mathrm{a}}$ Avenida, 1.100 Bairro dos Municípios - Balneário Camboriú /SC CEP 88337-300

Telefones para contato: (47) 3261-1235

e-mail:petrelli@univali.br

\section{Nome completo: Carlos Marcelo Ardigó}

Filiação institucional: Universidade do Vale do Itajaí - UNIVALI

Departamento: Marketing e Logística

Função ou cargo ocupado: Professor de Marketing e Logística da UNIVALI e IFES.

Endereço completo para correspondência: $5^{\mathrm{a}}$ Avenida, 1.100 Bairro dos Municípios - Balneário 
Camboriú /SC CEP 88337-300

Telefones para contato: (47) 3261-1324

e-mail: marcelo.ardigo@ifes.com.br

Nome completo: Nelson Casarotto Filho

Filiação institucional: Universidade Federal de Santa Catarina - UFSC

Departamento: Programa de Pós-Graduação em Engenharia da Produção

Função ou cargo ocupado: Professor Doutor

Endereço completo para correspondência: Centro Tecnológico; Campus Universitário - Trindade;

Caixa Postal 476; CEP 88040-900 - Florianópolis/SC.

Telefones para contato: (48) 3721-7104

e-mail: casarotto@deps.ufsc.br

Enviado em: 24/07/2012

Aprovado em: 02/08/2013 